\title{
High resolution 2-D fluorescence imaging of the mass boundary layer thickness at free water surfaces
}

\author{
C. Kräuter \\ christine.kraeuter@iup.uni-heidelberg.de \\ D. Trofimova \\ D. Kiefhaber
}

\section{N. Krah \\ B. Jähne}

\begin{abstract}
Universität Heidelberg, Institut für Umweltphysik, INF 229, 69120 Heidelberg, Germany Universität Heidelberg, Heidelberg Collaboratory for Image Processing (HCI), Heidelberg, Germany Universität Heidelberg, Institut für Umweltphysik, INF 229, 69120 Heidelberg, Germany Universität Heidelberg, Heidelberg Collaboratory for Image Processing (HCI), Heidelberg, Germany Universität Heidelberg, Institut für Umweltphysik, INF 229, 69120 Heidelberg, Germany Universität Heidelberg, Heidelberg Collaboratory for Image Processing (HCI), Heidelberg, Germany Universität Heidelberg, Institut für Umweltphysik, INF 229, 69120 Heidelberg, Germany Universität Heidelberg, Heidelberg Collaboratory for Image Processing (HCI), Heidelberg, Germany Universität Heidelberg, Institut für Umweltphysik, INF 229, 69120 Heidelberg, Germany Universität Heidelberg, Heidelberg Collaboratory for Image Processing (HCI), Heidelberg, Germany
\end{abstract}

A novel 2-D fluorescence imaging technique has been developed to visualize the thickness of the aqueous mass boundary layer at a free water surface. Fluorescence is stimulated by high-power LEDs and is observed from above with a low noise, high resolution and high-speed camera. The invasion of ammonia into water leads to an increase in $\mathrm{pH}$ (from a starting value of 4), which is visualized with the fluorescent dye pyranine. The flux of ammonia can be controlled by controlling its air side concentration. A higher flux leads to basic $\mathrm{pH}$ values ( $\mathrm{pH}>\mathrm{7}$ ) in a thicker layer at the water surface from which fluorescent light is emitted. This allows the investigation of processes affecting the transport of gases in different depths in the aqueous mass boundary layer. In this paper, the chemical system and optical components of the measurement method are presented and its applicability to a wind-wave tank experiment is demonstrated.

[DOI: http://dx.doi.org/10.2971/jeos.2014.14016]

Keywords: 2-D imaging, air-sea gas exchange, boundary layer visualization, LED induced fluorescence

\section{INTRODUCTION}

While far away from air-water interfaces, trace gases in both phases are mixed by turbulence, the turbulent eddies cannot penetrate through the surface. Therefore, close to the water surface in the boundary layers, molecular diffusion is the dominant transport mechanism to exchange gases between air and water. After decades of intensive research there are still open questions concerning the mechanisms driving airsea gas exchange. In investigations of gas transfer across the wind-driven water surface, laser-induced fluorescence (LIF) techniques have been applied to visualize vertical concentration profiles. Since the water side mass boundary layer is thin $(20-200 \mu \mathrm{m})$, a high resolution far better than $10 \mu \mathrm{m}$ is needed to resolve such profiles [1, 2]. Thus, these measurements are not well suited for studying a wind-driven wavy water surface and most studies are limited to tanks with gridstirred turbulence, e.g. [3]. Another disadvantage of these 1-D profile measurements is their inability to resolve twodimensional horizontal inhomogeneities in the near-surface flow. The breaking of waves for example can create turbulence close to the surface, which locally enhances gas transfer [4, 5].

The interactions of non-breaking waves with currents and the instability of the wind-induced shear flow create characteristic 2-D flow patterns, including elongated near-surface vortices that are aligned with the wind [6]-[8]. The additional turbu- lence that is created from these motions has been shown experimentally to enhance mass transfer [9]. To study these processes in detail, a visualization technique capable of imaging the horizontal structure of the boundary layer is needed. Currently, this is only possible with thermal imaging, visualizing the transfer of heat [10]-[12]. However, it is subject to discussion if near-surface turbulence affects the transport of heat and gases in the same manner $[13,14]$.

This paper presents a novel fluorescence-based technique for the visualization of the 2-D structures of the aqueous mass boundary layer. The method is a radical departure from all previously used LIF techniques. Instead of measuring vertical concentration profiles, the concentrations are imaged horizontally, while fluorescence is stimulated by high-power LEDs. The principle is based on an idea of Hiby [15] to investigate gas absorption in falling films. The very interdisciplinary method combines high resolution imaging with a system of chemical reactions to make concentrations visible. By carefully optimizing this technique, it is possible to transfer it to large wind-wave facilities. 


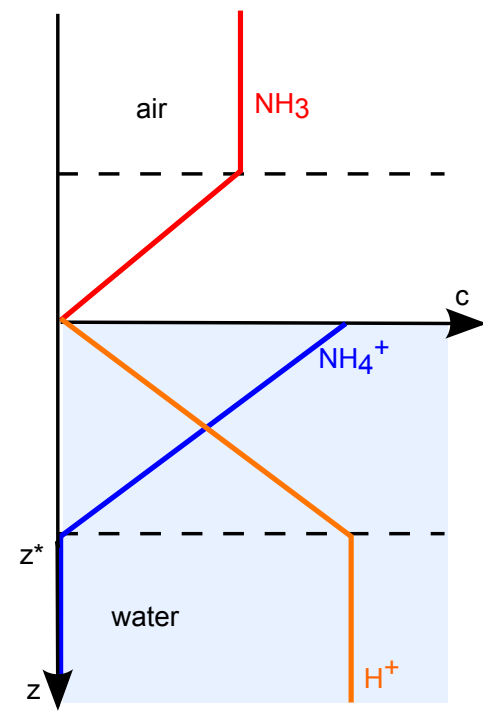

(a)

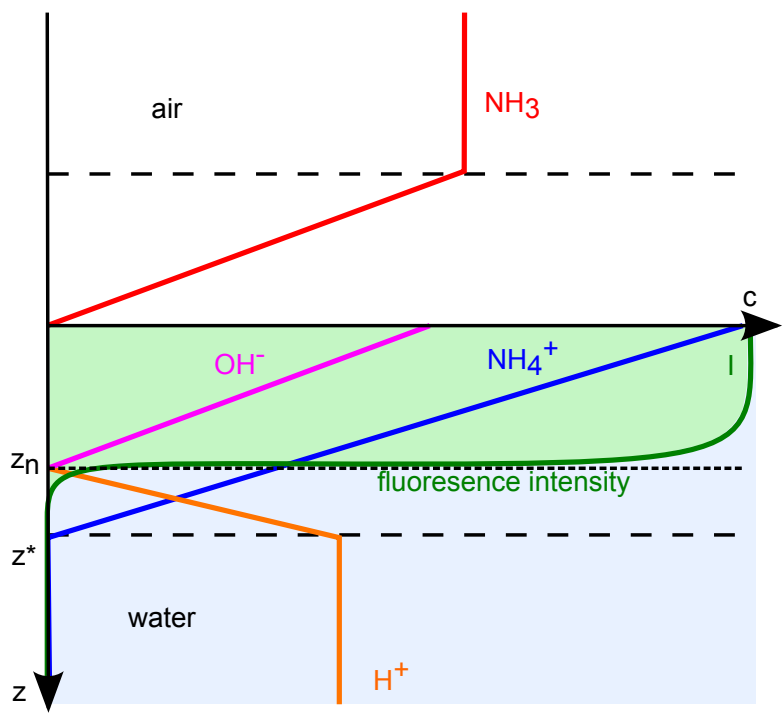

(b)

FIG. 1 Schematic concentration profiles in air and water over depth, for low (a) and high (b) air side concentration of ammonia $\left(\mathrm{NH}_{3}\right)$ and its reaction product, ammonium $\left(\mathrm{NH}_{4}^{+}\right)$. The alkaline fraction $\left(z_{n}\right)$ of the mass boundary layer $\left(z^{*}\right)$ emits fluorescent light with an almost constant intensity.

\section{MEASUREMENT PRINCIPLES}

The visualization relies on chemical mechanisms which are shortly outlined below. The main idea is to transform the concentration gradient of a gas into a gradient in $\mathrm{pH}$ value which can be visualized by a fluorescent indicator. A gradient in $\mathrm{pH}$ can be generated by observing the invasion of an alkalinereacting tracer from air into an acid solution. Therefore, ammonia $\left(\mathrm{NH}_{3}\right)$ is chosen as a trace gas and injected into the sealed air space of a wind-wave tank. In the air far away from the surface, the tracer is well-mixed by turbulence and there is no concentration gradient (see Figure 1(a)). At the surface, ammonia is solved in slightly acid water and the concentration drops. Since the transport of ammonia through the boundary layer is slow, the loss of ammonia near the surface cannot be compensated and a concentration gradient forms in steady state conditions.

Due to low $\mathrm{pH}$ values in the solution of hydrochloric acid in water, ammonia rapidly reacts with available hydrogen ions $\left(\mathrm{H}^{+}\right)$to produce ammonium $\left(\mathrm{NH}_{4}^{+}\right)$which accumulates in the boundary layer and hydrons are depleted near the surface. Ammonium is diffused downwards; charge conservation forces an equal, but opposite flux of hydrons (see Figure 1(a)). In the situation sketched in Figure 1(a), with a certain ammonia concentration the $\mathrm{pH}$ value has increased to 7 at the surface and virtually all the hydrons have reacted to ammonium.

If the air side ammonia concentration is increased and ammonia accumulates at a faster rate at the water surface, additional hydrons can only be provided through autoprotolysis of water. This leads to a net production of hydroxide $\left(\mathrm{OH}^{-}\right)$and consequently to the formation of an alkaline layer. The depth of the neutral layer $z_{n}(\mathrm{pH}=7$, Figure $1(\mathrm{~b}))$ depends on the air side concentration of ammonia.

The alkaline layer can be made visible by adding a $\mathrm{pH}$ sensitive dye to the water. When excited at approximately $455 \mathrm{~nm}$, the fluorescent $\mathrm{pH}$ indicator pyranine emits light only at
$\mathrm{pH}$ values greater than 7 . Around the depth of the neutral layer $z_{\mathrm{n}}$, the $\mathrm{pH}$ increases rapidly due to the logarithmic dependence of the $\mathrm{pH}$ on $\left[\mathrm{H}^{+}\right]$concentration. Therefore, the lower boundary of the fluorescing layer is well defined. Since the fluorescence has an almost binary behavior with a constant intensity over the alkaline layer, the depth-integrated fluorescence is linearly related to the depth of the neutral layer $z_{n}$. The neutral layer depth depends on the thickness of the aqueous mass boundary layer and the concentration of ammonia in the air. If the later is kept constant, it is therefore possible to visualize the two-dimensional structure of the mass boundary layer. This provides key insights into the mechanisms driving air-water gas exchange. Absolute measurements of the neutral layer thickness are possible after a calibration of the imaging system.

\section{OPTICAL COMPONENTS AND SIMULATIONS}

To realize the method explained above, a careful selection, dimensioning, and optimization of a number of components is crucial. Bandpass filtering of the fluorescence and emission of the light source is required in order to yield the highest possible intensity while suppressing direct reflections from the water surface. Likewise, the choice of bulk $\mathrm{pH}$ value and concentration of the indicator have a significant influence on the quality of the measurements. Key components will be discussed in detail in the following.

\subsection{Fluorescent Indicator}

Indicators are molecules, which exist in two forms in aqueous solutions, a protonized form ( $\mathrm{IH}$ ) and a deprotonized form $\left(\mathrm{I}^{-}\right)$. For pyranine (or HPTS, 8-hydroxypyrene-1,3,6trisulfonic acid, $\left.\mathrm{C}_{16} \mathrm{H}_{7} \mathrm{Na}_{3} \mathrm{O}_{10} \mathrm{~S}_{3}\right)$, the indicator used in our study the two components are in equilibrium at a $\mathrm{pH}$ slightly larger than 7 ( $\mathrm{pK} \approx 7.3[17,18]$ ). Both components can be excited to fluoresce, but different wavelengths of light are required. This is shown in Figure 2(a). The alkaline absorption 
exploited in this technique peaks at $455 \mathrm{~nm}$ (green solid line) while for the acid component a shorter wavelength at $403 \mathrm{~nm}$ is needed for excitation [16]. However, the absorption spectra overlap, as the acid component still absorbs a significant amount of light up to $440 \mathrm{~nm}$. This has to be considered when using broadband light sources like LEDs.

The dashed green (alkaline) and red (acid) lines show the emission spectra for excitation at $454 \mathrm{~nm}$ [16]. The alkaline emission is orders of magnitude larger. Since the total water depth in our wind-wave tank is about $100 \mathrm{~cm}$, the integrated fluorescence of the acid component can reach similar orders of magnitude as the integrated signal originating from the thin upper surface layer. Indeed, at $\lambda=525 \mathrm{~nm}$, the ratio of the fluorescence intensity at $\mathrm{pH}=4$ and $\mathrm{pH}=9$ is approximately $10^{-4}$ in Figure 2(b) and therefore $100 \mu \mathrm{m}$ of the alkaline boundary layer yield the same projected intensity as $100 \mathrm{~cm}$ of the acid bulk. To suppress this background bulk fluorescence, an absorbing dye, which absorbs the emitted light can be mixed to the water.

\subsection{Excitation}

Because a two dimensional patch on the water surface needs to be illuminated, a (monochromatic) Laser cannot be used easily. With the recent progress in LED technology, sufficient intensities can also be achieved with high-power LED light sources. The used blue LEDs (Cree XLamp XP-E) emit a broad spectrum in a range of approx. 430-540 nm. Since fluorescence of the acid component of pyranine is stimulated by light below $440 \mathrm{~nm}$ a long-pass yellow color filter (Schneider Kreuznach GG 455) is used to suppress light below $450 \mathrm{~nm}$.

Additional filters are required at the long wavelength end to separate the excitation light from the fluorescence. A shortpass filter (Optic Balzers DT-Blue) is used to suppress the light source emission above $490 \mathrm{~nm}$. The filtered LED spectrum is shown as the blue line in Figure 2(a).

\subsection{Emission}

Additional filters are required on the camera end to fully suppress reflections of the light sources from the water surface which overlay the fluorescence signal. A green band pass filter is used ( $534 \times 20 \mathrm{~nm}$, Edmund Optics) which has an optical density of 8 below $515 \mathrm{~nm}$ (see Figure 2).

The intensity of reflections and of the fluorescence can be estimated and compared to confirm that the suppression is sufficient. For a flat water surface, the reflected intensity is

$$
I_{\mathrm{R}}=\int_{520 \mathrm{~nm}}^{550 \mathrm{~nm}} I_{0} \frac{\Omega_{\mathrm{C}}}{\Omega_{\mathrm{L}}} R T_{\mathrm{R}}(\lambda) \mathrm{d} \lambda
$$

Because of the specularity of the water surface, all reflections are directed and the camera only sees light reflected into the solid angle $\Omega_{C}=\pi B^{2} / d^{2}$, where $B$ is the radius of the camera aperture and $d=140 \mathrm{~cm}$ is the distance from camera/light source to water surface. Because the light sources are larger than the camera aperture, light is reflected into the larger solid angle $\Omega_{\mathrm{L}}=A_{\mathrm{LED}} / d^{2}$ (where $A_{\mathrm{LED}}=25 \mathrm{~cm}^{2}$ is the size of the light source) and the camera only captures the fraction

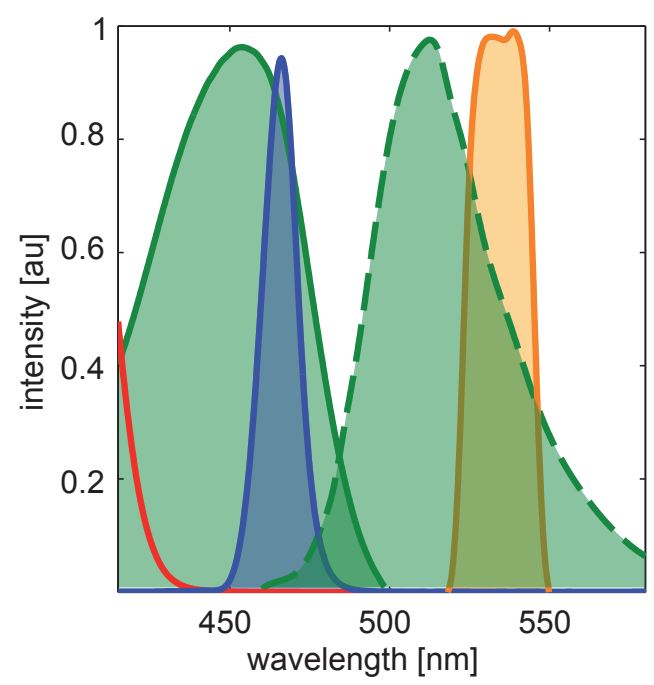

(a)

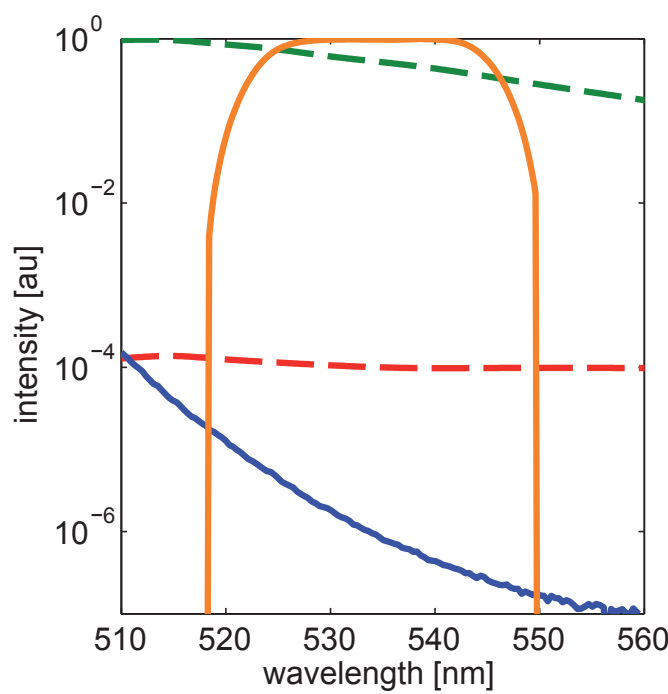

(b)

FIG. 2 The absorption (green and red solid lines) and emission (green and red dashed lines) spectra of pyranine at a pH 8 (green) and a pH 3.5 (red) are shown [16]. The blue solid line shows the filtered emission spectra of the used light source and in orange the transmission of the green band pass filter in front of the optical lens is shown in linear (a) and logarithmic scale (b).

$\Omega_{\mathrm{C}} / \Omega_{\mathrm{L}}$ of the total reflected intensity. In addition, only the fraction $R=0.02$ of the light is reflected at the water surface, the rest is transmitted. The green band pass filter in front of the camera filters most reflected light, this is accounted for by the factor $T_{\mathrm{R}} \approx 1 \times 10^{-8}$.

The intensity of the fluorescence on the other hand is given by

$$
I_{\mathrm{F}}=\int_{520 \mathrm{~nm}}^{550 \mathrm{~nm}} I_{0} \frac{\Omega_{\mathrm{C}}}{4 \pi} \eta T_{\mathrm{F}}(\lambda) \mathrm{d} \lambda
$$

Because fluorescence is isotropic (and emits into the full $4 \pi$ solid angle), only the fraction $\Omega_{\mathrm{C}} / 4 \pi$ of the total fluorescence is captured by the camera. The quantum efficiency $\eta$ is close to 1 [16] for pyranine; $T_{\mathrm{F}} \approx 0.33$ accounts for the fact that the spectral window of the camera is narrower than the distribution of fluorescence (orange line in Figure 2). 


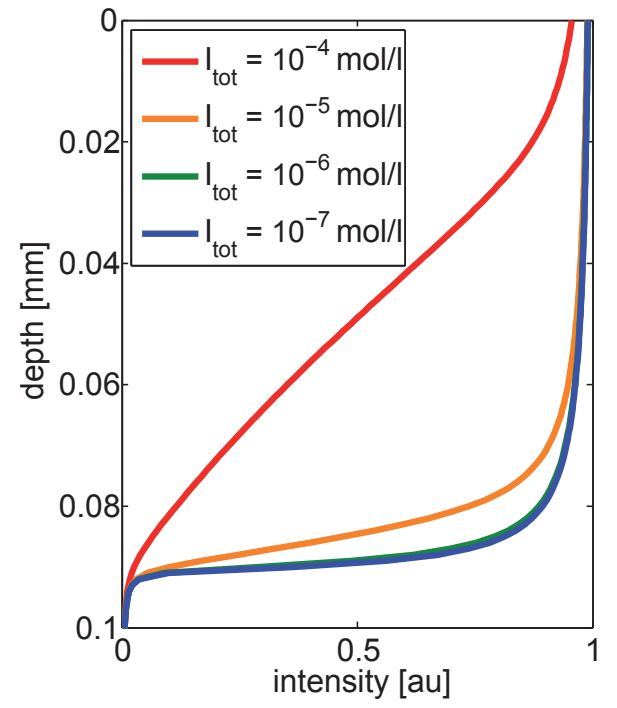

(a)

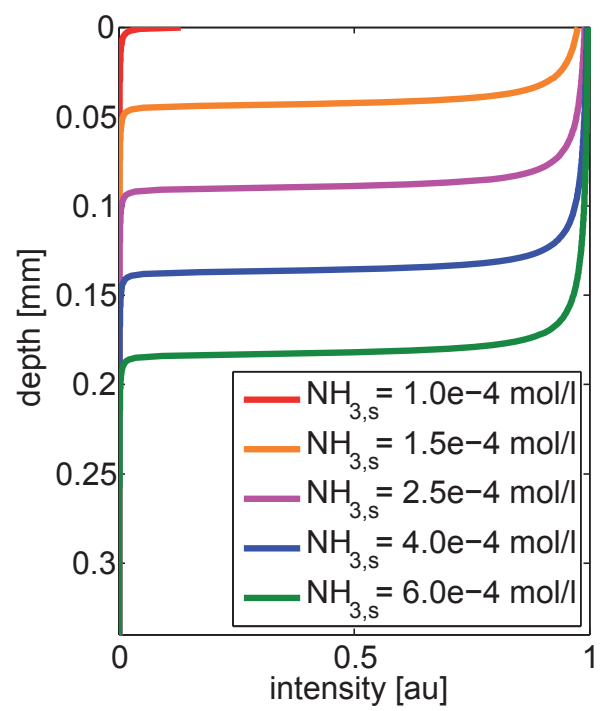

(b)

FIC. 3 Simulated depth profiles of fluorescence intensity for varying concentrations of (a) pyranine with a constant surface concentration of ammonia $\left(2.5 \times 10^{-4} \mathrm{~mol} / \mathrm{l}\right)$ and (b) ammonia with a constant concentration of pyranine $\left(10^{-6} \mathrm{~mol} / \mathrm{l}\right)$. The boundary layer thickness $\mathrm{z}^{*}$ is set to $100 \mu \mathrm{m}$ and the $\mathrm{pH}$ value in the bulk is $4\left(\left[\mathrm{H}^{+}\right]=10^{-4} \mathrm{~mol} / \mathrm{l}\right)$.

The relative brightness of reflections is thus given by

$$
I_{\mathrm{R}} / I_{\mathrm{F}}=\int_{520 \mathrm{~nm}}^{550 \mathrm{~nm}} \frac{4 \pi}{\Omega_{\mathrm{L}}} \frac{R}{\eta} \frac{T_{\mathrm{R}}}{T_{\mathrm{F}}} \mathrm{d} \lambda<10^{-6} .
$$

Therefore, reflections from the water surface do not play a significant role in the measurements with the given set of filters.

\subsection{Simulation}

In Figure 1(b), an idealized florescence profile is shown, where only the alkaline layer emits light and fluorescence drops almost immediately as the neutral layer is passed. However, this behavior is not guaranteed, because large concentrations of the indicator molecules themselves can affect the $\mathrm{pH}$ value. On the other hand, low concentrations of the indicator directly translate into low total fluorescence output, decreasing the signal to noise ratio.

To find the most suitable concentrations of pyranine and ammonia, the intensity profile over the depth in the water has been simulated using a more realistic model [20] for the average ammonia/ammonium/hydron concentration profile in the boundary layer (surface renewal model for the case of a smooth water surface).

Considering autoprotolysis of the water, mass and charge conservation, the average normalized intensity can be computed numerically.

In Figure 3(a), depth profiles of intensity are shown for different concentrations of pyranine in the water. For high concentration, the fluorescence intensity increases slowly towards the surface (red line) as its $\mathrm{pH}$ change is buffered by the indicator. With decreasing concentrations, the intensity gradient becomes steeper. A concentration of $\left[\mathrm{I}_{\text {tot }}\right]=10^{-6} \mathrm{~mol} / 1$ is found to be the best compromise between total fluorescence strength and steepness of gradient and is used in the measurements. Before each measurement, hydrogen chloride and the dye are added and well mixed in the water of the facility.

In Figure 3(b) the effect of different surface concentrations of ammonia on the fluorescence profile is shown: Fluorescence starts at the surface, when the ammonia concentration is sufficient to deplete the hydrons up to $\mathrm{pH}=7$ (see Section 2). A further increase above this threshold concentration causes a linear increase of the alkaline layer thickness. Hence, by controlling the air side concentration of ammonia, it is possible to increase the thickness of the fluorescent alkaline layer to probe the hydrodynamics in different distances from the water surface.

\section{EXPERIMENTAL SET-UP}

Figure 4(b) is a sketch of the set-up at the large Aeolotron windwave facility at the Institute of Environmental Physics in Heidelberg. The tank is annular, with an inner diameter of $9 \mathrm{~m}$ and a water channel width of $0.6 \mathrm{~m}$. The mean water depth is $1 \mathrm{~m}$, the closed, gas tight air space has a height of $1.4 \mathrm{~m}$. A high resolution, high-speed and low noise scientific CMOS camera (pco.edge by PCO AG, Kelheim, Germany) is mounted in the focal point of a large planoconvex BK7 lens (diameter $d=0.32 \mathrm{~m}$, focal length $f=2 \mathrm{~m}$ ). This lens and the $135 \mathrm{~mm}$ standard camera lens form an object-space telecentric lens [21]. This ensures a constant magnification factor even at changing water height due to waves.

The surface patch seen by the camera is excited by $6 \times 25$ blue high power LED arrays through a window from the roof of the facility. The footprint size is $20 \times 25 \mathrm{~cm}$, corresponding to a resolution of $0.09 \mathrm{~mm} /$ pixel. Due to their high power dissipation, the light sources are flashed to avoid excessive heating. Custom LED drivers are used that allow changing LED brightness and flash duration. To avoid motion blur of the fast moving structures at the water surface, an exposure time of less than $0.5 \mathrm{~ms}$ is required. Maximum frame rate for data acquisition is $100 \mathrm{~Hz}$.

In addition to this boundary layer visualization technique, the 3-D water surface shape and thermal structures can be measured simultaneously at the same footprint with an imaging 


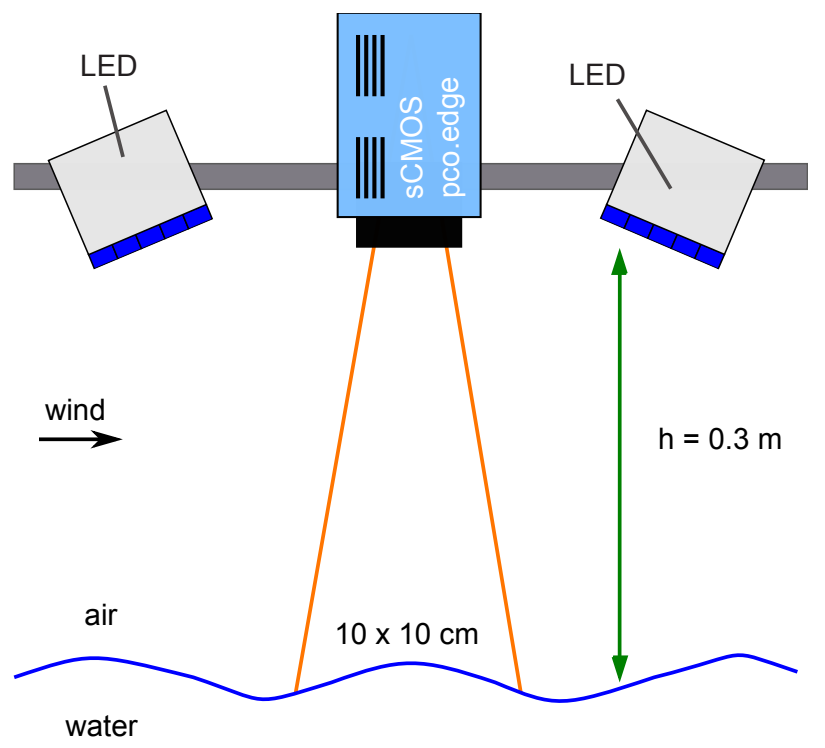

(a)

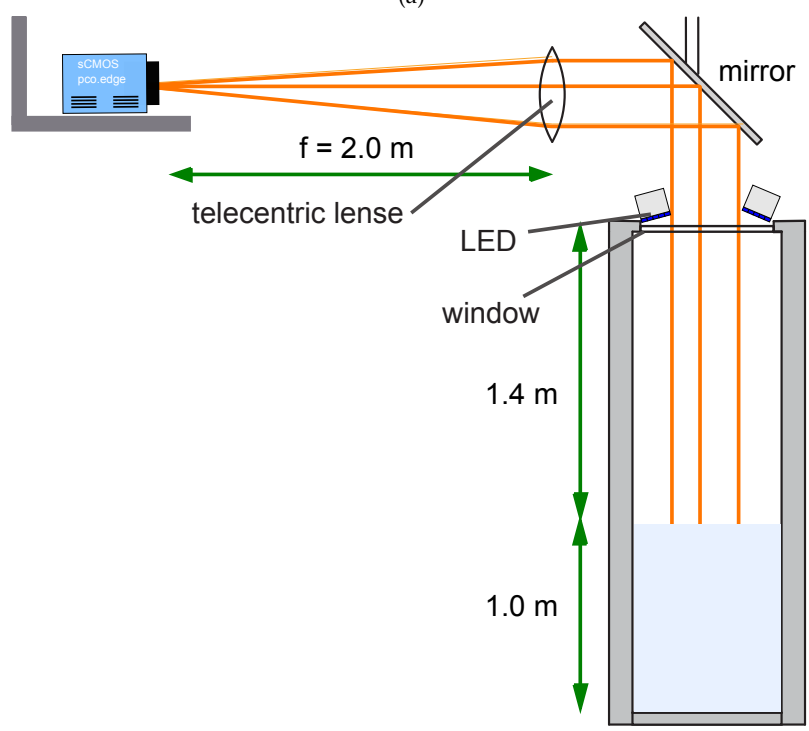

(b)

FIG. 4 (a) Sketch of the test set-up containing a scientific CMOS camera (pco.edge) and $2 \times 25$ blue high power LEDs which are mounted over the water surface at a small linear wind-wave tank. Figure (b) shows the set-up at a large ring form wind-wave facility (Aeolotron).

slope gauge [21] and a thermal camera. This gives the unique possibility to visualize the horizontal structures of gas and heat transfer and to study their effect on the wave field simultaneously.

Proof-of-concept measurements have been conducted in a small test wind-wave facility at the Heidelberg Aeolotron lab. This set-up is shown in Figure 4(a). Here the camera and two LED arrays are mounted on a rail $30 \mathrm{~cm}$ above the water surface. A standard $50 \mathrm{~mm}$ camera lens is used as telecentric imaging is not necessary due to the small relative height changes (1-3 mm). Image sequences with $100 \mathrm{fps}$ and a spatial resolution of about $50 \mu \mathrm{m} / \mathrm{pixel}$ are taken with a footprint of about $10 \times 10 \mathrm{~cm}$ at the water surface.

For the experiments, 221 of deionized water with $10^{-6} \mathrm{~mol} / 1$ of pyranine and a $\mathrm{pH}$ value of 4 is prepared. The water height at the measuring spot is $3 \mathrm{~cm}$. Ammonia is injected slowly into the air space $\left(\mathrm{V}_{\text {air }}=3001\right)$ by using a bubble flask containing a $10 \%$ solution of ammonia, which is flushed with fresh air. The flux rate of $20 \mathrm{ml} / \mathrm{min}$ is controlled with a custom flow controller and wind is generated by the facility's turbine. The air side ammonia concentration over time is tracked with a UV spectrometer. Therefore it is possible to monitor and control the air side concentration of ammonia and hence vary the thickness of the alkaline layer. This enables us to investigate the turbulent surface renewal in the water .

\section{RESULTS AND CONCLUSIONS}

In Figure 5(a) and 5(b), the two dimensional structures of the exchange of ammonia on a $4 \times 7 \mathrm{~cm}^{2}$ surface patch are shown. The images were taken at two different wind speeds; $1.5 \mathrm{~m} / \mathrm{s}$ (Figure 5(b)) and $5.5 \mathrm{~m} / \mathrm{s}$ (Figure 5(a)). From the example images it is clear that structures occur at very different scales for varying wind speeds. In the images, only fluorescence from the surface layer is visible, bulk fluorescence is suppressed. In Figure 5(c) a thermal image of the water surface recorded with an infrared camera (CMT 256 by Thermosensorik, Erlangen, Germany) at a wind speed of $1.5 \mathrm{~m} / \mathrm{s}$ is shown in false color. The footprint is identical with the one in Figures 5(a) and 5(b). Both in the fluorescence and thermal images, streaks that are more or less aligned with the wind direction (top to bottom) are visible. These streaks are caused by surface convergence and divergence zones. The alignment of these zones is due to near-surface vortices whose rotation axis is aligned with the wind [6]. The structures in Figure 5(b) and 5(c) are very similar, but fine details may be hidden in the thermal image 5(c) due to the low resolution and the more than 100-times larger diffusivity in water for heat than for ammonia.

For the first time, an imaging system with a high spatial and temporal resolution is available to investigate the mechanisms driving gas transfer in two horizontal dimensions. This is possible by the dedicated set-up described in this paper, which makes it possible to image the thickness of the mass boundary layer in a large wind-wave facility with high spatial $(0.1 \mathrm{~mm})$ and temporal $(10 \mathrm{~ms})$ resolution. We are able to image time resolved gas and heat transfer and study their dependence on the wave field simultaneously and collocated. By a controlled change of the thickness of the alkaline layer it is possible to investigate the depth dependence of turbulence eddies in the water. This can help to resolve the open questions regarding the scalability of transfer velocities for different gas species and heat.

\section{ACKNOWLEDGEMENTS}

This work is based on a presentation at the "1st EOS Topical Meeting on Frontiers of Optical Imaging" held in Murten $(\mathrm{CH})$ in September 2013. We gratefully acknowledge financial support by the DFG within the framework of the Graduiertenkolleg GRK 1114, 'Optical Techniques for Measurement of Interfacial Transport Phenomena'. The authors also want to thank Wolfgang Mischler and Leila Nagel for their technical assistance in using the image acquisition system. 


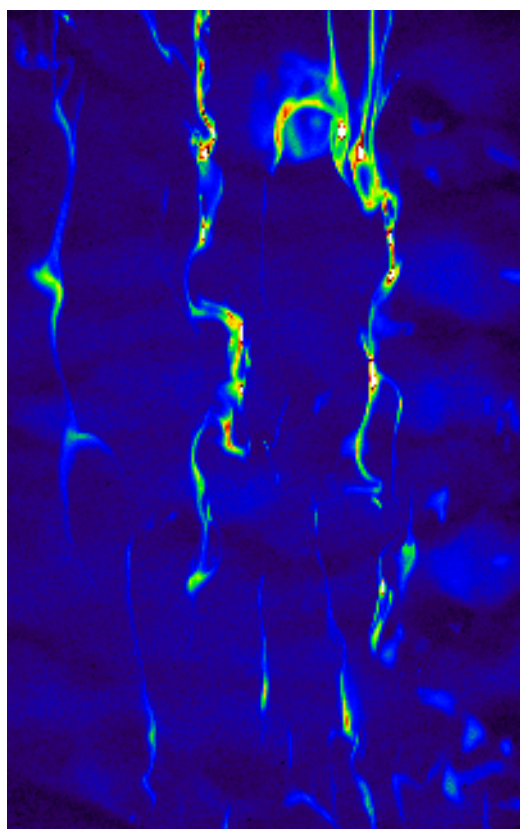

(a)

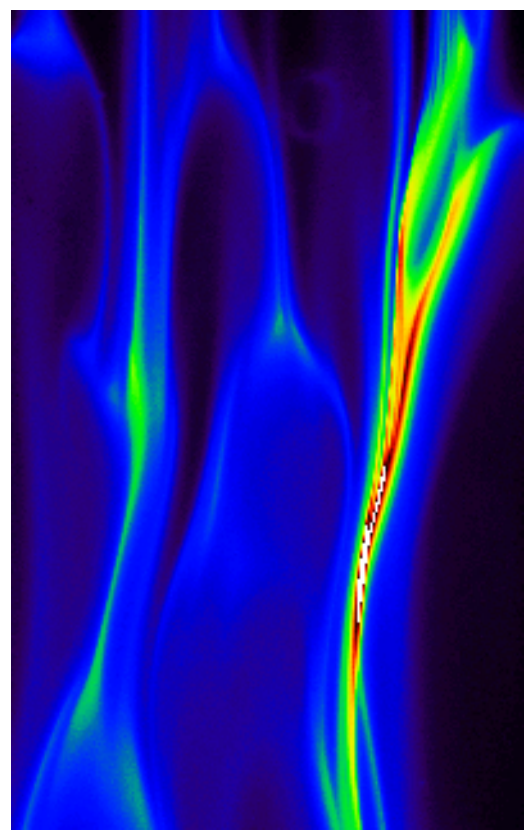

(b)

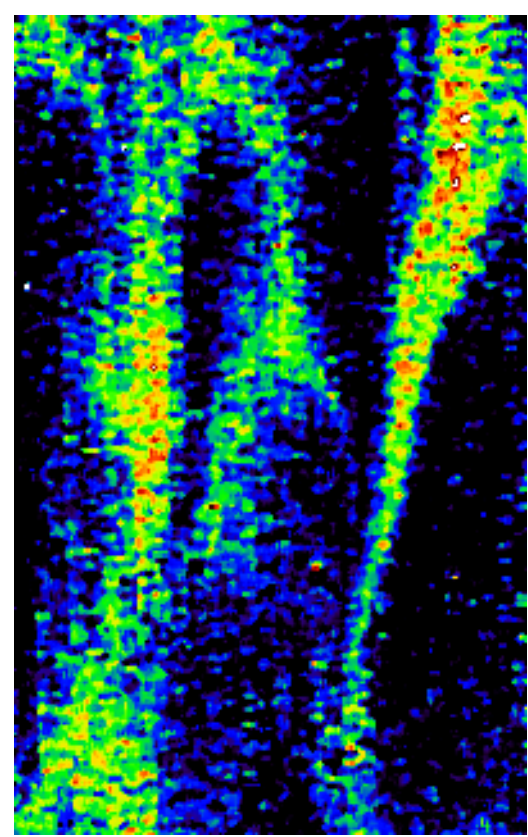

(c)

FIG. 5 Image of the water surface $\left(4 \times 7 \mathrm{~cm}^{2}\right)$ showing two dimensional horizontal structures of the mass boundary layer thickness $(\mathrm{a}, \mathrm{b})$ and water surface temperature $(\mathrm{c})$ in false color. The images were recorded at a wind speed of approx. $5.5 \mathrm{~m} / \mathrm{s}$ (a) and $1.5 \mathrm{~m} / \mathrm{s}(\mathrm{b}, \mathrm{c}$ ).

\section{References}

[1] B. Jähne, K. O. Münnich, R. Bösinger, A. Dutzi, W. Huber, and P. Libner, "On the parameters influencing air-water gas exchange," J. Geophys. Res. 92, 1937-1950 (1987).

[2] T. Münsterer, and B. Jähne, "LIF measurements of concentration profiles in the aqueous mass boundary layer," Exp. Fluids 25, 190-196 (1998).

[3] I. Herlina, and G. H. Jirka, "Experiments on gas transfer at the airwater interface induced by oscillating grid turbulence," J. Fluid. Mech. 594, 183-208 (2008).

[4] W. L. Peirson, J. W. Walker, C. Welch, and M. L. Banner, “Defining the enhancement of air-water interfacial oxygen exchange rate due to wind-forced microscale waves," in Transport at the air sea interface - Measurements, models and parameterizations, C. S. Garbe, R. A. Handler, and B. Jähne, eds., 119-131 (SpringerVerlag, Heidelberg, 2007).

[5] S. Banerjee, D. Lakehal, and M. Fulgosi, "Surface divergence models for scalar exchange between turbulent streams," Int. J. Multiphas. Flow. 30, 963-977 (2004).

[6] W. K. Melville, R. Shear, and F. Veron, "Laboratory measurements of the generation and evolution of Langmuir circulations," J. Fluid. Mech. 364, 31-58 (1998).

[7] W.-T. Tsai, S.-M. Chen, and C.-H. Moeng, "A numerical study on the evolution and structure of a stress-driven free-surface turbulent shear flow," J. Fluid. Mech. 545, 163-192 (2005).

[8] J. Schnieders, C. S. Garbe, W. L. Peirson, G. B. Smith, and C. J. Zappa, "Analyzing the footprints of near-surface aqueous turbulence: An image processing-based approach," J. Geophys. ResOceans 118, 1272-1286 (2013).

[9] F. Veron, and W. K. Melville, "Experiments on the stability and transition of wind-driven water surfaces," J. Fluid. Mech. 446, 25-65 (2001).

[10] U. Schimpf, C. Garbe, and B. Jähne, "Investigation of transport processes across the sea surface microlayer by infrared imagery," J. Geophys. Res. 109, C08S13 (2004).
[11] A. T. Jessup, C. J. Zappa, and H. Yeh, "Defining and quantifying microscale wave breaking with infrared imagery," J. Ceophys. Res. 102, 23145-23153 (1997).

[12] C. J. Zappa, W. E. Asher, A. T. Jessup, J. Klinke, and S. R. Long, “Microbreaking and the enhancement of air-water transfer velocity," J. Geophys. Res. 109, C08S16 (2004).

[13] W. E. Asher, H. Liang, C. J. Zappa, M. R. Loewen, M. A. Mukto, T. M. Litchendorf, and A. T. Jessup, "Statistics of surface divergence and their relation to air-water gas transfer velocity," J. Ceophys. Res. 117, C05035 (2012).

[14] M. A. Atmane, W. E. Asher, and A. T. Jessup, "On the use of the active infrared technique to infer heat and gas transfer velocities at the air-water free surface," J. Geophys. Res. 109, C08S14 (2004).

[15] J. W. Hiby, "Eine Fluoreszenzmethode zur Untersuchung des Transportmechanismus bei der Gasabsorption im Rieselfilm," Warme Stoffubertrag. 1, 105-116 (1968) in German.

[16] 0. S. Wolfbeis, E. Fürlinger, H. Kroneis, and H. Marsoner, "Fluorimetric analysis," Fresen. Z. Anal. Chem. 314, 119-124 (1983).

[17] Y. Avnir, and Y. Barenholz, “pH determination by pyranine: medium-related artifacts and their correction," Anal. Biochem. 347, 34-41 (2005).

[18] R. Barnadas-Rodríguez, and J. Estelrich, "Photophysical changes of pyranine induced by surfactants: evidence of premicellar aggregates," J. Phys. Chem. B 113, 1972-1982 (2009).

[19] J. R. Lakowicz, Principles of fluorescence spectroscopy (3rd edition, Springer, New York, 2006).

[20] B. Jähne, P. Libner, R. Fischer, T. Billen, and E. J. Plate, “Investigating the transfer process across the free aqueous boundary layer by the controlled flux method," Tellus 41, 177-195 (1989).

[21] D. Kiefhaber, S. Reith, R. Rochholz, and B. Jähne, "High-speed imaging of short wind waves by shape from refraction," J. Europ. Opt. Soc. Rap. Public. 9, 14015 (2014). 